1 MacLennan A, Wilson D, Taylor A. The escalating cost and prevalence of alternative medicine. Prew Med 2002;35:166-73

2 Eisenberg D, Davis R, Ettner S, Appel S, Wilkey S, Van Rompay M, et al. Trends in alternative medicine use in the United States, 1990-1997. JAMA 1998;280:1569-75

Mombelli B, Gismondo MR. The use of probiotics in medical practice. Int J Antimicrob Agents 2000;16:531-6.

Pirotta M, Gunn J, Chondros P. "Not thrush again!" Women's experience of post-antibiotic vulvovaginitis. Med J Aust 2003;179:43-6.

5 Nyirjesy P, Weitz M, Grody T, Lorber B. Over-the-counter and alternative medicines in the treatment of chronic vaginal symptoms. Obstet Gynecol 1997:90:50-3.

6 Chapple A, Hassell K, Nicolson M, Cantrill J. 'You don’t really feel you can function normally': women's perceptions and personal management of vaginal thrush. J Reprod Infant Psychol 2000;18:309-19.

7 Pizzorno L, Pizzorni J, Murray M. Natural medicine instructions for patients. Edinburgh: Churchill Livingstone, 2002.

8 Bluestein D, Rutledge C, Lumsden L. Predicting the occurrence of antibiotic-induced candidal vaginitis (AICV). Fam Pract Res J 1991; 11:319-26.

9 Pirotta M, Gunn J, Chondros P, Grover S, Hurley S, Garland S. Study protocol. The PAV trial: does lactobacillus prevent post-antibiotic vulvovaginal candidiasis? Protocol of a randomised controlled trial [ISRCTN24141277]. BMC Fam Pract 2004;5:5.
10 O'Brien P, Fleming T. A multiple testing procedure for clinical trials. Biometrics 1979:35:549-56.

11 Nelson D, Bellamy S, Gray T, Nachamkin I. Self-collected versus providercollected vaginal swabs for the diagnosis of bacterial vaginosis: an assessment of validity and reliability. J Clin Epidemiol 2003;56:862-6.

12 Pocock S. When to stop a clinical trial. BMJ 1992;305:235-6.

13 Redondo-Lopez V, Cook RL, Sobel JD. Emerging role of lactobacilli in the control and maintenance of the vaginal bacterial microflora. Rev Infect Dis 1990;12:856-79.

14 McGroarty JA. Probiotic use of lactobacilli in the human female urogenital tract. FEMS Immunol Med Microbiol 1993;6:251-64.

15 Klebanoff SJ, Hillier SL, Eschenbach DA, Waltersdorph AM. Control of the microbial flora of the vagina by $\mathrm{H} 2 \mathrm{O} 2$-generating lactobacilli. J Infect Dis 1991;164:94-100.

16 Sobel JD, Faro S, Force RW, Foxman B, Ledger WJ, Nyirjesy PR, et al. Vulvovaginal candidiasis: epidemiologic, diagnostic, and therapeutic considerations. Am J Obstet Gynecol 1998;178:203-11.

17 Sobel JD, Chaim W. Vaginal microbiology of women with acute recurrent vulvovaginal candidiasis. J Clin Microbiol 1996;34:2497-9.

18 Fidel PL Jr. The protective immune response against vaginal candidiasis: lessons learned from clinical studies and animal models. Int Rev Immunol 2002;21:515-48.

doi 10.1136/bmj.38210.494977.DE

\title{
Identification of potential candidates for varicella vaccination by history: questionnaire and seroprevalence study
}

\author{
Eithne MacMahon, Lisa J Brown, Sarah Bexley, David C Snashall, Dipti Patel
}

Guidance from the Joint Committee on Vaccination and Immunisation regarding varicella vaccination of workers in healthcare settings is imminent. ${ }^{1}$ The new recommendations will advise that all those with a negative or uncertain history of chickenpox or shingles at pre-employment assessment should be tested for varicella zoster virus IgG. Vaccination with the newly licensed varicella vaccine will be advised for those with a seronegative result.

A history of chickenpox has a high positive predictive value for immunity among healthcare workers in Europe, where the seroprevalence is as high as $98.5 \%{ }^{2}$ The validity of a history of chickenpox is unknown in those from tropical countries, however, where the mean age of infection is in early adulthood. ${ }^{3}$ Guy's and St Thomas' Hospital NHS Trust in inner London has some 8000 staff and 4700 healthcare students of increasingly heterogeneous origins. ${ }^{45}$ We conducted a questionnaire and seroprevalence study at the hospital to ascertain the relations between history of chickenpox, countries of birth and residence, and serological status.

\section{Participants, methods, and results}

From September 2001 to July 2002 a nurse administered questionnaire was completed for 747 staff and students consecutively attending preemployment screening. Country of birth or of first residence was noted, together with age range during subsequent residence in other countries. Recruits were asked about prior chickenpox or shingles, with details recorded. Serology was requested in line with usual practice. Immune status was determined by using the Diamedix enzyme immunoassay kit for varicella zoster virus IgG (Miami, FL, USA).
Of $629(84 \%)$ recruits tested, six yielded equivocal results and were excluded from further analysis. Those who denied or were unsure of past infection were considered as one group. We assigned participants to "temperate" or "tropical" subgroups according to country of birth or first residence. We compared differences in seroprevalence and proportions of groups with a positive history by using the $\chi^{2}$ test; we also analysed other variables (unadjusted and adjusted) using logistic regression.

The table shows the results. Additional information about prior chickenpox (nature and site of rash, residual scar) did not increase the positive predictive value. Shingles had a positive predictive value of $100 \%$, however, with all 22 participants testing IgG positive. Twenty nine participants in the temperate group had not lived solely in temperate zones during their first 12 years and had a reduced risk of testing seropositive (odds ratio 0.35 compared with those born and brought up in a temperate climate)-similar to that of those born and brought up in a tropical climate (odds ratio 0.36).

Participants from Sub-Saharan Africa and the Caribbean were disproportionately represented among the 52 seronegative participants (29\% (15) and $17 \%$ (9) respectively, compared with just 18\% (113) and 5\% (31) respectively among all new recruits). Among participants with a history of prior infection, the false positive rate was $9.3 \%$ in the tropical group versus $3.7 \%$ in the temperate group $(\mathrm{P}=0.019)$ (table).

This article was posted on bmj.com on 23 July 2004: http://bmj.com/cgi/ doi/10.1136/bmj.38170.691956.AE
Department of Infection, Guy's and St Thomas' Hospital NHS Trust, London SE1 7EH Eithne MacMahon consultant Lisa J Brown research scientist

Occupational Health Department Guy's and St Thomas' Hospital NHS Trust Sarah Bexley specialist nurse adviser

Occupational Health Department Guy's, King's, and St Thomas' School of Medicine, London SE1 9RT

David C Snashall senior lecturer Dipti Patel lecturer

Correspondence to: E MacMahon eithne.macmahon@ gstt.sthames.nhs.uk

BMJ 2004;329:551-2 
Results and statistical analysis of differences between temperate and tropical subgroups

\begin{tabular}{|c|c|c|c|c|}
\hline & $\underset{(n=623)}{\text { All }}$ & $\begin{array}{c}\text { Temperate } \\
(\mathrm{n}=431)^{\star}\end{array}$ & $\begin{array}{c}\text { Tropical } \\
(n=192)^{*}\end{array}$ & $P$ value \\
\hline Average age (years) $\dagger$ & 27.5 & 25.0 & 34.1 & \\
\hline \multicolumn{5}{|l|}{ Sexf } \\
\hline Men $(\%)$ & $115(18.6)$ & $84(19.5)$ & $31(16.3)$ & \\
\hline Women (\%) & $503(81.4)$ & $344(80.4)$ & $159(83.7)$ & \\
\hline Seroprevalence of varicella zoster virus (\%) & 571 (91.7) & 409 (94.9§) & $162(84.4 \S)$ & $<0.001$ \\
\hline False positive history (\%)ף & $23(5.0)$ & $13(3.7)$ & $10(9.3)$ & 0.019 \\
\hline Sensitivity (\%) & 77.2 & 83.9 & 60.5 & $<0.001$ \\
\hline Specificity (\%) & 55.8 & 40.9 & 66.7 & 0.065 \\
\hline Positive predictive value (\%) & 95.0 & 96.3 & 90.7 & \\
\hline Negative predictive value (\%) & 18.2 & 12.0 & 23.8 & \\
\hline
\end{tabular}

${ }^{*}$ Temperate regions are defined as United Kingdom, rest of Europe, North America, Antipodes, Middle East, and Indian sub-continent; tropical regions are defined as sub-Saharan Africa, South East Asia, and

Caribbean and Central America.

†Age was recorded for 451 individuals (temperate, $n=327$; tropical, $n=124$ ). Among the 451 individuals for whom age was known, the odds ratio for seropositivity in the tropical versus the temperate group was 0.48 , modified to 0.50 after adjustment for age group.

¥Sex was recorded in 618 individuals.

$\S 95 \%$ confidence intervals: temperate $92.8 \%$ to $97.0 \%$; tropical $79.2 \%$ to $89.6 \%$.

П1-positive predictive value.

\section{Comment}

Candidates for varicella vaccination (seronegative staff) will inevitably be missed if a blanket policy of screening by history alone is implemented. As shown here, their number will increase considerably if groups with a significantly higher false positive rate account for a substantial proportion of the workforce.

The overall seroprevalence and positive predictive value are lower than figures usually quoted for healthcare workers in Europe, but the distribution of geographical origins largely explains the discrepancy. It is a weakness of this study that some of the countries defined as temperate in the questionnaire-for example, India-also contain regions with tropical climates. Serological testing of recruits from these areas should also be considered. Individuals born or raised in tropical climates should have serological screening regardless of a history of chickenpox.

\section{What is already known on this topic}

A history of chickenpox is a reliable indicator of past infection in temperate climates

\section{What this study adds}

Seronegative candidates for varicella vaccination will be missed if a blanket policy of screening by history alone is applied to people born or raised in tropical climates

We thank the Guy's and St Thomas' Hospital NHS Trust's occupational health nurses for conducting the questionnaire, its department of infection staff for laboratory work and secretarial help, and Sue Chinn for help with statistical analysis.

Contributors: EMacM and DP designed the study, wrote the paper and did the statistical analysis. LJB did data entry, manipulation, and analysis. SB coordinated data collection and entered the data. DCS contributed throughout the study. $\mathrm{EMacM}$ is the guarantor.

Funding: None.

Competing interests: In the past five years, EMacM has received sponsorship from Launch Diagnostics Biokit, GlaxoWellcome, SmithKlineBeecham Pharmaceuticals, and Aventis Pasteur MSD towards the cost of attending conferences. DP has been funded by GlaxoSmithKline to give a talk on a subject unrelated to this study.

Ethical approval: St Thomas' Research Ethics Committee.

1 Department of Health. www.dh.gov.uk/policyandguidance healthandsocialcaretopics/greenbook (See new chapter 34) (accessed 16 July 2004).

2 Vandersmissen G, Moens G, Vranckx R, de Schryer A, Jacques P. Occupational risk of infection by varicella zoster virus in Belgian healthcare workers: a seroprevalence study. Occup Environ Med 2000;57:621-6.

3 Garnett GP, Cox MJ, Bundy DAP, Didier JM, St Catharine J. The age of infection with varicella-zoster virus in St Lucia, West Indies. Epidemiol Infect 1993;110:361-72.

Buchanan J, Edwards N. Nursing numbers in Britain: the argument for workforce planning. BMJ 2000;1067-70.

Rogers J. Recruiting in hard times. BMJ 1997;315(suppl):S2. (http:// bmj.bmijournals.com/cgi/content/full/315/7122/S2-7122)

doi 10.1136/bmj.38170.691956.AE

\section{A memorable teacher}

\section{What am I doing here?}

In our separate ways, we and Professor Harold Scarborough started at the Welsh National School of Medicine in the early $1950 \mathrm{~s}$ - he as professor of medicine, and we as first year clinical medical students. As the coauthor of a standard textbook of physiology (Bell, Davidson, and Scarborough), his name was already well known.

From the outset, he introduced a clear break from the didactic nature of teaching to which we were accustomed. His technique was always testing and interrogatory, probing our logic and beliefs and the validity of our observations. A classic example from one of the final medicine examination papers at the time was "What is the value of routine clinical examination of the tongue?" He told us later that he would have considered awarding full marks for anyone who had simply written "None." This was at a time when examination of the tongue was a preliminary ritual to any clinical examination.

His intention was to make us think clearly, and this was usually achieved with an element of theatricality. A slow soft spoken voice, a sharp intake of breath at our replies, and a light footed spin often made it difficult to know whether we had said something of brilliance or stupidity. When we finally managed to divine the correct answer to the question asked, it remained in the memory.

His address at a medical graduation ceremony in Cardiff was also memorable and remains highly relevant. He began by commenting that the graduates had been subjected to a great deal of questioning in their recent examinations, but asked them to consider one further question, and explained that this was one that they should ask themselves at regular intervals throughout their careers. It was "What am I doing here?"

There then followed an analysis and amplification of the question: "What am I doing here? What am I doing here? What am I doing here? What am I doing here?" One can imagine the implications of the question, and some of the possible answers that might suggest themselves.

It was a typical performance of a fine and memorable teacher.

David Crosby retired surgeon

John Henry Jones retired physician, University Hospital of Wales, Cardiff 